\title{
EDITORIAL
}

DOI:10.5055/jom.2018.0433

\section{Sourcing of opioid analgesics for nonmedical use: Are veterinarians the latest frontier?}

\author{
Cayley Russell, MA; Benedikt Fischer, PhD; Thiago M. Fidalgo, MD, PhD
}

The nonmedical use of prescription opioid analgesics (POAs) in North America (ie, the United States [US] and Canada), and the consequential public health crisis, are an acute challenge for public health. POA use rates have increased multifold since the early 2000's, resulting in major consequential population-level harms. Concretely, 12.5 million US adults ( 4.7 percent of the population) engaged in non-medical POA use (ie, use without medical direction or prescription) in 2015, compared to 4.7 million in 2007 (1.9 percent of the population); rates of POA-related morbidity (eg, hospitalizations, treatment admissions, etc.) and mortality (eg, overdose deaths) in North America have steeply increased to rates exceeding other major leading causes of premature death. ${ }^{1-4}$ Most recently, there were 22,598 annual POA-related overdose deaths in the US (2015), and 2,816 in Canada (2016).5,6

This POA-related public health crisis has been driven by exceptionally high POA dispensing rates; strong correlations between POA use levels and related morbidity/mortality outcomes have been well-documented. ${ }^{7}$ While acute harms, such as hospitalizations or overdoses, have occurred both in legitimate POA users (ie, patients) and non-medical users, excessive dispensing/prescribing patterns have facilitated large-scale diversion of POAs and subsequent non-medical use, implicating the medical system as a main contributor to this problem. ${ }^{8}$

Different medical specialties have facilitated extensive POA availability as key sources. For instance, primary care physicians are main prescribers of POAs, ${ }^{9}$ while pain medicine, surgery, and rehabilitation specialists had the highest POA prescription rates in the US (2007-2012). ${ }^{10}$ High prescribing rates exist among other specialties, such as internists, orthopedic surgeons, emergency department physicians, dentists, etc. ${ }^{9,11}$

Recently, various interventions to curb the high levels of POA use and diversion have been implemented across North America. For instance, prescriptionmonitoring programs (PMPs) to track prescriptions and mitigate potential 'doctor shopping' (ie, obtaining multiple prescriptions from different physicians), 'tamper-proof' formulations and take-back programs for POAs, and more restrictive prescribing guidelines have been implemented. ${ }^{12,13}$ Some of these interventions have demonstrated initial impacts at reducing undue POA availability and harms in select jurisdictions. ${ }^{14}$

However, there are good indications that these restrictive measures have created unmet demand and supply voids for POAs, forcing nonmedical users to alternative sources. ${ }^{15,16}$ Some of these have come in the form of clandestinely produced or imported potent POAs, such as fentanyl, which have spread rapidly across North America causing extensive harms including mortality. ${ }^{17}$ However, sourcing of POAs for nonmedical use from medical sources continues, and-based on multiple case studies and other anecdotal evidence-appears to increasingly include a novel source: veterinary practices. ${ }^{18}$

In veterinary practice, POAs are used for a variety of analgesic purposes and clinical indications in animals, such as anesthesia and pain relief. ${ }^{19}$ Veterinarians have access to a variety of POAs in high demand among nonmedical (human) users that are susceptible to diversion, including highly potent POAs, like carfentanil, and large quantities thereof, used specifically for analgesic purposes in large animals. ${ }^{20,21}$ Approximately 108,000 veterinary practices existed in the US, and 3,500 in Canada, in 2016, comprising a substantial number of potential sourcepoints for POAs in North America. ${ }^{22,23}$

Besides the range of POA products available, veterinarians are a unique source for POAs as they largely fall outside of control systems applied to human medicine. ${ }^{24}$ For instance, many North American subjurisdictions (ie, provinces/states) do not require veterinarians to report their $\mathrm{POA}$-prescribing 
to PMPs; those that do commonly are incompatible with established PMP technologies, rendering effective tracking difficult. ${ }^{24,25}$ Additionally, many veterinary clinics retain large quantities of POAs on-site as the principal dispensers of these drugs; furthermore, there are no limits on the amounts of POAs veterinarians can prescribe, which may aid the availability of large POA amounts for diversion or misuse. ${ }^{25,26}$

In this context, there have been reports of veterinarians pilfering POAs for personal use, and threequarters of a sample of US-based veterinarians indicated that they had worked with someone they knew had a substance abuse problem. ${ }^{27}$ Moreover, one-third reported that these drugs were easily accessible, rendering veterinary clinics particularly vulnerable to theft or misuse by employees, as well as robberies and burglaries. ${ }^{27}$ Further anecdotal evidence of POA diversion from veterinary sources has emerged, including that of patients purposely maiming their pets in order to acquire POAs. ${ }^{18,28}$ 'Vet shopping,' and return visits to veterinary clinics to obtain repeat POA prescriptions have also been reported. ${ }^{16}$ Specifically, tramadol-a synthetic POA commonly prescribed by veterinarians-has been in particularly high-demand due to its comparably cheap price. ${ }^{28}$ Other case reports include the diversion of POAs, including potent carfentanil, from veterinary clinics, and numerous carfentanil-related overdose deaths have now been cited across North America. ${ }^{26,29}$

Although mostly limited to anecdotal evidence, the diversion of POAs from veterinary sources appears to be a growing phenomenon, in the context of high demand yet increasingly restricted access for nonmedical POA use in North America. With veterinarians as a main source-point for POAs, and currently exempt from key monitoring controls, their potential contribution to non-medical POA sourcing appears to be growing, yet largely neglected by policy makers. As part of comprehensive interventions towards reducing the POA-related public health burden, including effective supply management, improved controls of the veterinary medicine sector ought to be a focus.

\section{ACKNOWLEDGEMENTS}

Dr. Fischer acknowledges funding from Canadian Institutes of Health Research (CHIR) for the Ontario CRISM node team (grant \#SMN-139150), which supported parts of the present study, as well as support from the Endowed Chair in Addiction Psychiatry, Department of Psychiatry, University of Toronto.
Cayley Russell, MA, Institute for Mental Health Policy Research, Centre for Addiction and Mental Health (CAMH), Toronto, Canada.

Benedikt Fischer, PhD, Institute for Mental Health Policy Research, Centre for Addiction and Mental Health (CAMH); Department of Psychiatry, University of Toronto; Institute of Medical Science (IMS), University of Toronto; Centre for Criminology \& Sociolegal Studies, University of Toronto, Toronto, Canada.

Thiago M. Fidalgo, MD, PhD, Addiction Unit (PROAD), Department of Psychiatry, Universidade Federal de São Paulo (UNIFESP), Sao Paulo, Brazil.

\section{REFERENCES}

1. Manchikanti L, Kaye AM, Knezevic NN, et al.: Responsible, Safe, and Effective Prescription of Opioids for Chronic NonCancer Pain: American Society of Interventional Pain Physicians (ASIPP) Guidelines. Pain Physician. 2017; 20(2S): S3-S92.

2. Center for Behavioral Health Statistics and Quality (CBHSQ): 2016 National Survey on Drug Use and Health: Detailed tables. Rockville, Maryland: Substance Abuse and Mental Health Services Administration (SAMHSA); 2017.

3. Murphy Y, Goldner EM, Fischer B: Prescription Opioid Use, Harms and Interventions in Canada: A Review Update of New Developments and Findings since 2010. Pain Physician. 2015; 18(4): E605-E614.

4. Substance Abuse and Mental Health Services Administration (SAMHSA): Results from the 2012 National Survey on Drug Use and Health: Summary of National Findings. Rockville, MD: Substance Abuse and Mental Health Services Administration (SAMHSA); 2013.

5. Government of Canada: National report: Apparent opioidrelated deaths. Ottawa, ON: Government of Canada; 2017.

6. National Institute for Drug Abuse (NIDA): National Overdose Deaths from Select Prescription and Illicit Drugs. Bethesda, Maryland; 2017.

7. King NB, Fraser V, Boikos C, et al.: Determinants of increased opioid-related mortality in the United States and Canada, 1990-2013: A systematic review. Am J Public Health. 2014; 104(8): e32-e42.

8. Fischer B, Rehm J: Revisiting the 'paradigm shift'in opioid use: Developments and implications 10 years later. Drug and Alcohol Review. 2017.

9. Volkow ND, McLellan TA, Cotto JH, et al.: Characteristics of Opioid Prescriptions in 2009. JAMA. 2011; 305(13): 1299-1301.

10. Levy B, Paulozzi L, Mack KA, et al.: Trends in opioid analgesic-prescribing rates by specialty, US, 2007-2012. Am J Prev Med. 2015; 49(3): 409-413.

11. Lev R, Lee O, Petro S, et al.: Who is prescribing controlled 
medications to patients who die of prescription drug abuse? Amer J Emer Med. 2016; 34(1): 30-35.

12. Kaye AD, Jones MR, Kaye AM, et al.: Prescription Opioid Abuse in Chronic Pain: An Updated Review of Opioid Abuse Predictors and Strategies to Curb Opioid Abuse: Part 1. Pain Physician. 2017; 20(2S): S93.

13. Fischer B, Rehm J, Tyndall M: Effective Canadian policy to reduce harms from prescription opioids: Learning from past failures. CMAJ. 2016; 188(17-18): 1240-1244.

14. Surratt HL, O'Grady C, Kurtz SP, et al.: Reductions in prescription opioid diversion following recent legislative interventions in Florida. Pharmacoepidemiol Drug Saf. 2014; 23(3): 314320.

15. Fischer B, Murphy Y, Jones W, et al.: Recent Developments in Prescription Opioid-related Dispensing and Harm Indicators in Ontario, Canada. Pain Physician. 2015; 18(4): E659-E662.

16. Bever L: The Horrifying Way Some Drug Addicts are Now Getting Their Fix. The Washington Post. 2017. Available at: bttps://www.washing tonpost.com/news/to-yourbealth/wp/2017/01/23/some-addicts-are-so-desperate-fordrugs-that-theyre-now-taking-medication-prescribed-topets/?utm_term=.863741dce818. Accessed June 24, 2017.

17. Howlett K, Woo A: Fentanyl's Deadly Path. The Globe and Mail. 2016. Available at: https://www.theglobeandmail.com/ news/national/how-fentanyl-is-getting-through-canadasborder/article29547443/. Accessed June 28, 2017.

18. Earl J: Addicts using pets to score drugs, veterinarians warn. CBS News. 2017. Available at: http://www.cbsnews.com/news/ addicts-turning-to-abusing-pets-to-score-drugs-veterinarianswarn/. Accessed June 24, 2017.

19. Ackerman N: Controlled Drugs in veterinary practices. Veterinary Nursing Journal. 2014; 29(4): 126-129.

20. Grimm KA, Lamont LA, Tranquilli WJ, et al.: Veterinary Anesthesia and Analgesia: The Fifth Edition of Lumb and Jones. Wiley; 2015.
21. Gussow L: Toxicology Rounds: Who Said the Opioid Crisis Couldn't Get Any Worse? Emergency Medicine News. 2016; 38(11): 1-29.

22. Canadian Veterinary Medical Association: Veterinary Demographics (2016). Ottawa, ON: Canadian Veterinary Medical Association; 2017.

23. American Veterinary Medical Association: Market Research Statistics: US Veterinarians 2016. Schaumburg, IL: American Veterinary Medical Association; 2017.

24. Simpson RJ: Prescription Drug Monitoring Programs: Applying a One-Size Fits All Approach to Human and Veterinary Medical Professionals, Custom Tailoring is Needed. $J$ Animal Environmental Law. 2013-2014; 1: 1-43.

25. Cima G: States track dispensing to counter drug fraud: Rules on veterinarians inconsistent among states. JAVMA News. 2017. Available at: bttps://www.avma.org/News/JAVMANews/Pages/ 170201a.aspx. Accessed June 24, 2017.

26. MacIvor A: Opioids prescribed for pets might be going to humans, vet warns. CBC News. 2017. Available at: http:// www.cbc.ca/news/canada/nova-scotia/pets-veterinariansopioids-drugs-1.4173607. Accessed June 24, 2017.

27. Geller J: Dark Shadows: Drug Abuse and Addiction in the Veterinary Workplace. DVM 360 Magazine. 2016. Available at: bttp://veterinarynews.dvm360.com/dark-shadows-drug-abuseand-addiction-veterinary-workplace. Accessed June 24, 2017.

28. Morgan R: People are Now Maiming their Pets to Score Drugs. New York Post. 2017. Available at: http://nypost.com/ 2017/01/16/people-are-now-maiming-their-pets-to-scoredrugs/. Accessed June 12, 2017.

29. Kounag N: Elephant tranquilizer to blame for at least 8 Ohio deaths. CNN. 2016. Available at: http://www.cnn.com/2016/09/ 06/health/carfentanil-deaths-obio/. Accessed June 12, 2017. 